en Serbie sur la création d'institutions de secours. M. Vladan Georgéwitch rappelle en effet qu'en 1870 il essaya lui-même de proposer la question à l'assemblée de l'Omladina.... « Mais, ajoute-t-il, on était trop engagé dans la lutte du libéralisme et du radicalisme. Ces deux grands mots préoccupaient seuls tous les esprits, on re put s'occuper de ma proposition.

"Plus tard, en 1871, j'ai traité ce sujet dans une brochure où j'exposai le plan d'après lequel on devait organiser chez nous les sociétés de secours; mais le ministère de la guerre seul me tint comple de ce travail.

« Lorsque je fus élu conseiller de Belgrade, je plaidai de toutes mes forces en faveur de la cause. Je demandai qu'on voulât au moins créer des établissements reconnus d'utilité publique en temps de paix. Je démontrai par des chiffres exacts les moyens de pourvoir à toutes les exigences sans aucune augmentation d'impòts...

M. Vladan Georgéwitch ne se laissa arrêter par aucun obstacle, et les documents que nous publions aujourd'hui disent suffisamment quel fut le résultat de ses efforts. C'est ainsi que, grâce à son activité persistante, et au moment où elle va connaître toutes les douloureuses épreuves de la guerre, la Serbie aura du moins la satisfaction de pouvoir combiner ses propres efforts avec les nôtres pour l'amélioration du sort de ses soldats.

\title{
FONDATION DE LA SOCIÉTÉ SERBE DE LA CROIX ROUGE
}

Rapport présenté au Comitẻ international de la Croix rouge, à Genève.

Au commencement de cette année, l'idée de la formation d'une Société serbe de la Croix rouge a été mise en avant au sein du "Casino civil " de Belgrade et a rencontré aussitòt parmi la population la plus vive sympathie.

Dans quelques séances préliminaires le projet de constitution de la dite société a été discuté. Il en est résulté l'ẻlaboration de statuts 


\section{2}

qui, présentés au Gouvernement de la principauté, ont obtenu sa sanction empressée. A la date du 6 février dernier, dans une réunion générale tenue au Casino de Belgrade, les fondements de la Société ont été jetés et un comité de quarante personnes, chargé de la direction des affaires de la Société, a été institué, conformément aux statuts précédemment votés.

Les premiers soins du Comité central ont été d'acquérir la sympathie des populations de la principauté et leur adhésion à son œuvre humanitaire. Il s'est adressé dans ce but à toutes les autorités civiles de l'intérieur du pays, avec la prière de faire comprendre à leurs administrés les bienfaits que la Société de la Croix rouge a déjà procurés à l'humanité, et en insistant sur l'utilité de la fondation d'une branche de la dite société en Serbie.

Le Comité central envoya en outre à to'utes les communes des exemplaires des statuts de la Société, accompagnés de la traduction de la Convention de Genève du 22 aoùt 1864, afin de faire connaître l'institution et son utilité.

Nous avons eu la satisfaction de constater que l'invitation du Comité central avait rencontré partout un accueil sympathique. Dans tous les chefs-lieux de département, qui sont en Serbie au nombre de seize, non compris Belgrade, dans six autres villes et dans sept villages il s'est formé des sous-comités qui sont en relations suivies avec le Comité central, et s'efforcent d'augmenter le nombre des membres de la Société.

Tout en cherchant à constituer en Serbie, pour la Société de la Croix rouge, une base solide 'qui la mette à même d'accomplir sa mission humanitaire, le Comité central s'est préoccupé de se mettre en relations avec les sociétés étrangères, ses sœurs, et en premier lieu avec le Comité international de Genève, qui est à leur tête.

Mais sachant que la Société serbe ne pourrait entrer en relations avec les autres sociétés de la Croix rouge que si le Gouvernement princier faisait officiellement acte d'accession à la Convention de Genève du 22 aoùt 1864, le Comité central s'adressa au Gouvernement de la principauté, en le priant d'adhérer à la dite Convention. Celui-ci, désirant assurer au pays les bienfaits de cet acte international, obtempéra immédiatement au désir du Comité central, et porta à la connaissance du Haut Conseil Fédéral qu'il accédait à 


\section{3}

la Convention. L'acte d'accession a été inséré au journal officiel de la principauté.

Les travaux du Comité central, à Belgrade, et des sous-comités dans l'intérieur de la principauté, ont consisté jusqu'à présent à gagner à la société, le plus d'adhésions possible et à recueillir les dons en argent et en nature résultant des souscriptions, cotisations, etc. Le nombre des membres de la Société est actuellement de 1572 et nous avons tout lieu d'espérer qu'il augmentera rapidement dans de notables proportions.

Belgrade, le 15 mai 1876.

\section{Le président du Comité central de la Société de la Croix rouge, archevêque métropolitain de Serbie,}

\section{MicheL.}

Le secrétaire du Comité central,

Milan St. Markovitz.

\section{BTATUTS}

DE LA SOctété CENTRALE SERBE DE LA CROIX Rouge POUR SEcours vOLONTAIRES AUX BLESSÉS ET MALADES EN TEMPS DE GUERRE

\section{$\$ 1$.}

La société qui s'est constituée sous le nom de "Société centrale serbe de la Croix rouge pour secours volontaires aux blessés et malades en temps de guerre " a pour but:

$1^{0}$ En temps de guerre : de coopérer, à còté de l'administration sanitaire de l'armée serbe, à l'assistance des soldats blessés ou malades et à l'administration des hôpitaux militaires, tout en se conformant aux prescriptions des autorités militaires.

$2^{\circ}$ En temps de paix: de préparer tout ce qui est nécessaire pour rendre cette assistance efficace en temps de guerre.

L'œuvre de la Société consiste donc:

a) A préparer, au moyen de ses ressources privèes, les établissements, le matériel et le personnel nécessaires pour recevoir et soigner les blessés et les malades en cas de guerre.

b) A venir en aide en temps de guerre aux institutions et établissements sanitaires de l'armée, par tous les moyens dont dispose la Société. 